\title{
Novel OBP genes similar to hamster Aphrodisin in the bank vole, Myodes glareolus
}

Romana Stopková1, Zbyněk Zdráhal ${ }^{2}$, Štěpán Ryba ${ }^{1}$, Ondřej Šedo ${ }^{2}$, Martin Šandera', Pavel Stopka ${ }^{1 *}$

\begin{abstract}
Background: Chemical communication in mammals involves globular lipocalins that protect and transport pheromones during their passage out of the body. Efficient communication via this protein - pheromone complex is essential for triggering multiple responses including aggression, mate choice, copulatory behaviour, and onset and synchronization of oestrus. The roles of lipocalins in communication were studied in many organisms and especially in mice (i.e. Mus musculus domesticus) which excrete Major Urinary Proteins (Mup) in excessive amounts in saliva and urine. Other mammals, however, often lack the genes for Mups or their expression is very low. Therefore, we aimed at characterization of candidate lipocalins in Myodes glareolus which are potentially linked to chemical communication. One of them is Aphrodisin which is a unique lipocalin that was previously described from hamster vaginal discharge and is known to carry pheromones stimulating copulatory behaviour in males.
\end{abstract}

Results: Here we show that Aphrodisin-like proteins exist in other species, belong to a group of Odorant Binding Proteins (Obp), and contrary to the expression of Aphrodisin only in hamster genital tract and parotid glands of females, we have detected these transcripts in both sexes of $M$. glareolus with the expression confirmed in various tissues including prostate, prepucial and salivary glands, liver and uterus. On the level of mRNA, we have detected three different gene variants. To assess their relevance for chemical communication we investigated the occurrence of particular proteins in saliva, urine and vaginal discharge. On the protein level we confirmed the presence of Obp2 and Obp3 in both saliva and urine. Appropriate bands in the range of 17-20 kDa from vaginal discharge were, however, beyond the MS detection limits.

Conclusion: Our results demonstrate that three novel Obps (Obp1, Obp2, and Obp3) are predominant lipocalins in Myodes urine and saliva. On the protein level we have detected further variants and thus we assume that similarly as Major Urinary Proteins in mice, these proteins may be important in chemical communication in this Cricetid rodent.

\section{Background}

Lipocalins are known to be involved in many important biological processes, of which one of them is chemical communication. Due to a conservative tertiary structure forming typical beta barrel all lipocalins share ability to bind various ligands of different size and structure. For some of the lipocalin members there already exists evidence for causing significant behavioural effects by their specific pheromonal ligands. The main lipocalin proteins studied to date in association with chemical communication are the mouse Major Urinary Proteins (Mup) secreted predominantly in the urine and saliva and

\footnotetext{
* Correspondence: pstopka@natur.cuni.cz

'Department of Zoology, Faculty of Science, Charles University in Prague, Viničná 7, Prague, CZ-128 44, Czech Republic
}

Odorant Binding Proteins (Obp) with predominant site of expression in nasal tissue.

In mice, urine is an important source of chemical information, frequently investigated by conspecifics and having the ability to elicit various behavioural responses including aggression, dominance and mate choice [1-6]. The major components of mouse urine are the Major Urinary Proteins, constituting approximately $90 \%$ of all proteins in the urine. The amount of Mups excreted to urine is sexually dimorphic, with males expressing more Mups than females on both mRNA and protein level [7]. However even the lower amount of Mups in female urine may be sufficient as a signal of reproductive status, advertising the beginning of oestrus [8]. Various substances with pheromonal effect bound to Major Urinary 
Proteins were identified [3,9-11] and many of studies have brought the evidence that these Mup-ligand complexes [12-14], unbounded ligands and potentially Mup itself $[4,12]$ have effect upon the reproductive physiology of the signal/pheromone receiver.

Mups are coded by high number of genes which have probably evolved by recent gene duplication and form a cluster of 21 intact genes and 21 pseudogenes on chromosome $4[15,16]$. Such variability leads to the hypothesis that urine marks may serve for individual odour discrimination in mice [17]. However, high variability of Mups is clearly demonstrated only in particular subspecies of the house mouse Mus musculus domesticus and derived laboratory strains and is completely missing in some other rodent species.

Contrary to Mup sexual dimorphism biased to males there exists another lipocalin in hamsters, called Aphrodisin, of which the expression is attributed only to females. Aphrodisin is a lipocalin that was isolated from hamster vaginal discharge by Singer et al. [18] and is detected (or it's ligands) via the vomeronasal organ of male hamsters. The term Aphrodisin originates from its functional property to stimulate copulatory behaviour in male hamsters which were exposed to vaginal odour of females [19]. Analysis of various fractions of female vaginal discharge led to the conclusion that this lipocalin itself is responsible for various behavioural and physiological effects [18]. However later studies revealed that recombinant Aphrodisin produced in E. coli was clearly less active than Aphrodisin isolated from vaginal discharge [20]. It, however, remains to be determined whether 3D structure of lipocalins produced in bacteria corresponds to the structure detected in mammals that naturally produce aphrodisin. The effect of Aphrodisin may be enhanced by various ligands that were detected in hamster vaginal smears by Briand et al. [21] who described five specific compounds which are also present in insect pheromone blends. Analysis of the Aphrodisin expression sites revealed that the main tissue expressing this gene is vagina with the Bartholin's glands [22-24], cervix uteri, low level of expression was detected also in ovaries [23], and moreover in the parotid glands of females [24]. Expression of Aphrodisin is attributed only to females, nevertheless there is weak evidence for the absence of Aphrodisin in males, because there is only one paper [24] from available literature where the researchers analyzed male saliva and parotid glands and had found no expression. To our knowledge, there is as yet no published information on the expression of Aphrodisin in male bulbourethral glands which are homologous to female Bartholin's glands.

According to the protein sequence analysis and of exon-intron organization, hamster Aphrodisin falls within the monophyletic group of lipocalins (described as cluster X) including i.a. mouse Obps, rat Obp1f and Probasin $[25,26]$. Protein sequence comparison of Aphrodisin shows the highest similarity with the mouse Obp1a and Obp1b ( 50\%) [24] and 40\% similarity with the rat Obp1f [21]. Our presented novel sequences on the translated protein level share 59\% similarity with this hamster lipocalin. In mice Odorant Binding Protein forms heterodimer containing $18 \mathrm{kDa}$ and $19 \mathrm{kDa}$ subunits called Obp1a and Obp1b, which are expressed mainly in the main olfactory epithelium [27]. In our previous paper [16] we have analyzed public databases (NCBI) and proposed that the mouse Obp forms a gene cluster of more than only two Obp variants. On the $\mathrm{X}$ chromosome in the range of $0.5 \mathrm{Mb}$ there are at least 8 Obp genes, including one pseudogene and these genes can be further divided into three structural groups [16]. Lipocalins linked to the monophyletic cluster X [25], including all mouse Obp genes, homologous rat Obp genes from $\mathrm{X}$ chromosome and Aphrodisin share typical sequence characterized by extra two cystein residues forming CxxxC motif [16]. In addition to the conservative disulfide bond tightening the beta-barel to the $\mathrm{C}$ terminal tail [28] this extra two cystein residues form a second disulfide bridge characteristic for this group of lipocalins [29]. Interestingly, this motif also occurs in some other lipocalin genes, namely Probasin, with chromosomal location next to the Obp cluster, and recently described hamster's Male Specific Salivary Protein (MSP) and Female Lacrimal Protein (FLP) [30-32]. It suggests that despite the different names, these lipocalins belong to the Obp group and may also act as odorant/pheromone carriers, however, this has to be further studied.

Obps are known to bind various odorant molecules [33] and are found through the wide spectrum of animals [27,34-38]. The suggested role of Obp in olfaction predicts the transport of hydrophobic odorants across the aqueous mucous layer to the odorant receptors [39-41], termination of olfactory signals by removing the odorants from the receptor [35] or enhancing the signal by maintain the active conformation of olfactory receptors and thus contribute to signal amplification $[42,43]$. Boudjelal et al. [44] pointed out that the receptor for Obp is presented in number of tissues unrelated to olfaction and therefore suggested that the function of this lipocalin may not be limited only to odorant transport. Another feature of lipocalins is their ability to scavenge for toxic substances or act as an antibacterial defence. The scavenger function of porcine and bovine Obp was suggested [45] in an experiment which clearly showed that Obp binds with high affinity HNE (4hydroxy-2-nonenal), a toxic compound derived from lipid peroxidation, and therefore can protect living cells 
from damage caused by oxidative stress by removing cytotoxic compounds from the nasal mucus. The antibacterial defence arises from the ability of some lipocalins (i.e. called siderocalins) to bind bacterial siderophores and thus prevent the bacterial growth [46-48]. There are few candidate siderocalins in mammals (Lcn1, Lcn2 and Lcn12), however it is possible that due to the conservative tertiary structure some other lipocalins may also share this ability [49].

The main goal of this paper was to identify dominant transcripts/proteins in Myodes glareolus that are secreted to urine, saliva and vaginal secrets and propose potential roles for these proteins. Bank voles are a target species in various ecological studies and our previous analysis revealed that individuals of both sex contain candidate proteins of approximately $17-20 \mathrm{kDa}$ in the urine. However, there is little available information on the mechanisms that bank voles use to mark their territories, attract individuals of opposite sex and how is this information transmitted to other individuals. Therefore, this study employed gene expression and gene characterization techniques to uncover a potential group of proteins that may play a role in chemical communication in this species.

\section{Results}

\section{M. glareolus voles express three novel Obp genes/ transcripts in different secretory tissues}

RT-PCR was conducted using mRNA from secretory tissues (prostate, preputial glands, salivary glands, liver). The samples were derived from wild caught $M$. glareolus to ascertain whether $M$. glareolus express transcripts for candidate lipocalins that are known to carry volatiles facilitating chemical communication. Use of a hamster Aphrodisin specific primer set generated clear bands in the expected area. M. glareolus amplicons were purified and cloned with TA TOPO kit and consequently the total of 28 clones were each forward and reverse sequenced. This analysis revealed three unique cDNA amplicons described as Obp1 [GQ219783], Obp2 [GQ219784], and Obp3 [GQ219785] (Figure 1) which were similar to hamster Aphrodisin (75\% identity) and mouse Obp1a and Obp1b (72\% identity) from public NCBI database. Sequencing further revealed that 20 sequences - identified as Obp1 - were present in individuals of both sex and across all tissues analyzed except male prostate. Three nucleotide polymorphisms were revealed in two of the female samples (i.e. liver, parotid glands) causing $1 \%$ difference (i.e. $99 \%$ identity) from Obp1 for which we use the term Obp1b. However, this could be a result of heterozygous effect. The Obp2 transcripts were detected in male prostate (3 clones, i.e. 6 sequences) whilst Obp3 was detected from a single clone using cDNA from submandibular glands.
More detailed analysis of translated transcripts revealed that the novel Obp genes have typical lipocalin signatures including GxW motif [50], two conservative cystein residues characteristic for most of the lipocalins, and extra two cysteins forming the CxxxC motif (see Figure 1). This motif is a specific feature of hamster Aphrodisin described as a position of the second disulphide bond in this lipocalin [29]. To add, all mouse Obps, Rat Obp1f, and other lipocalins compared in Figure 2 share the same feature.

Contrary to hamsters, the expression of novel genes is not female specific but is present in individuals of both sex and across different tissues studied. Although, these novel sequences were highly similar to hamster Aphrodisin (75\% identity) we use more general term Obps (i.e. Obp stands for Odorant Binding Protein) with which they share $72 \%$ identity (Figure 2) because the term Aphrodisin presupposes its aphrodisiac function which was not assessed for novel proteins in this study.

2-D electrophoresis and MS analyses confirmed the presence of detected Obps in the urine and saliva but not in vaginal flushes

Image analysis of 2D gels of urinary, salivary and vaginal samples revealed protein spots in the predicted region of $\mathrm{pI}$ (3.9-5.1) and in the MW range of 18-20 kDa. After tryptic digestion protein spots were subjected to MALDI-MS/MS and LC-MS/MS analysis. MS/MS data were primarily searched against to the Obp library containing DNA- derived sequences. Subsequently, the data were searched against NCBI protein database to avoid random false positives caused by small size of the Obp library. MS/MS data of peptides which have not matched to Obp library in Mascot database search were manually evaluated. Based on MS/MS data three Obp proteins were unambiguously identified: Obp2 and two Obp3 isoforms (Obp3-A and Obp3-B). These proteins correspond to the most intensive spots in $2 \mathrm{D}$ gel of the salivary sample. Only Obp2 and Obp3-A were identified in the urinary sample (see Figure 3). The transcript corresponding to Obp1 gene was abundant on the level of mRNA, however, remained undetected on the level of protein. Reasons for this failure may involve modifications that changed its $\mathrm{pI}$ or that the concentration of Obp1 protein was low and thus below MS identification limits. Furthermore, the Obp proteins were present also in less intense spots but their identification was based on sequence regions identical for all variants not allowing correct determination of the particular variant and they are not further discussed in this study. Results of MS/MS analysis of three main Obp variants in salivary samples are summarized in Figure 4.

Sequence coverage ranged from $63 \%$ (Obp2) to $77 \%$ (Obp3-B) when non-specific trypsin cleavage were taken in account (enzyme "semiTrypsin"). While detected 


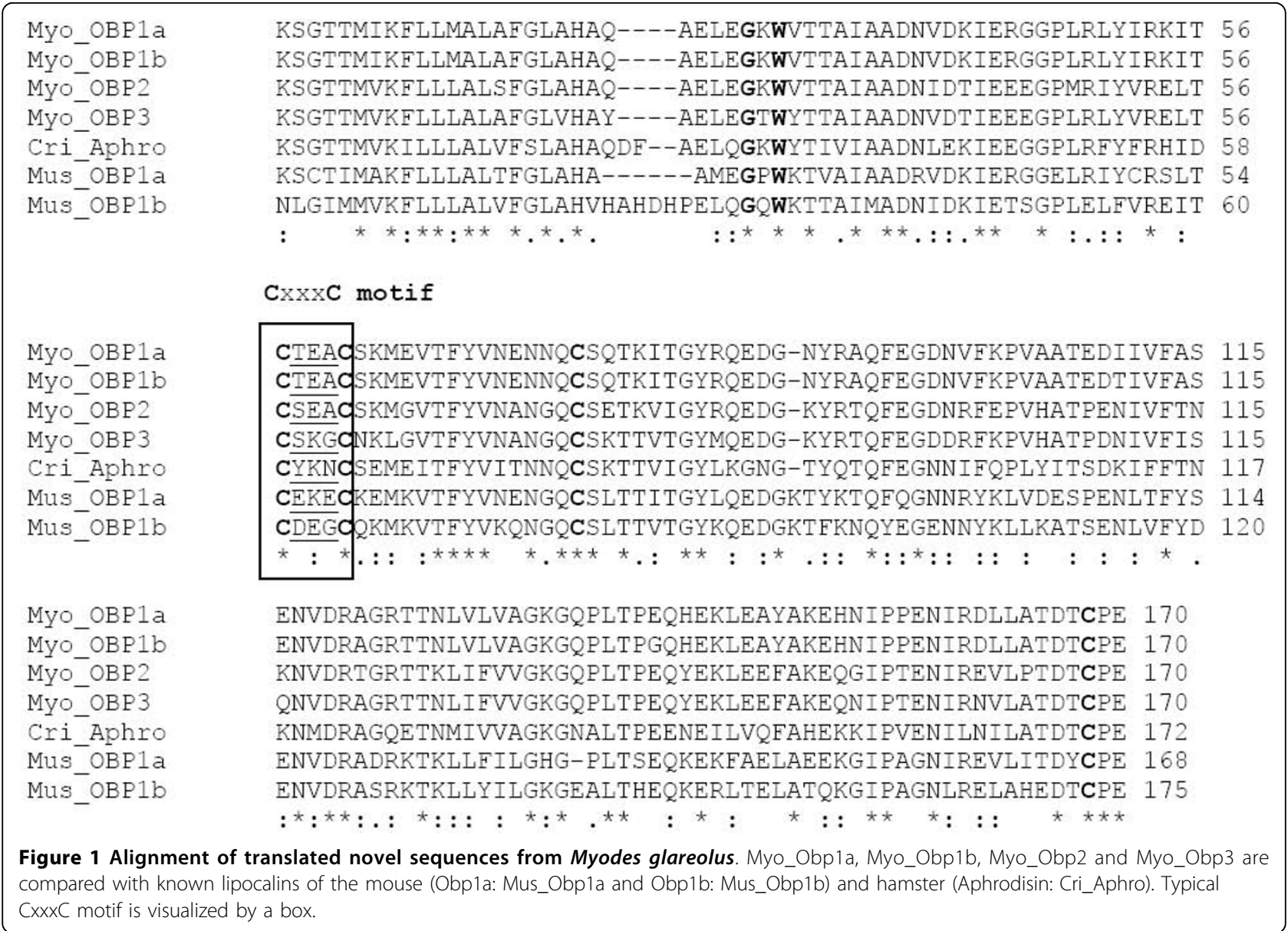

parts of Obp2 sequence were completely in agreement with cDNA-derived sequence, Obp3 protein sequence showed several differences from cDNA-derived sequence indicating the presence of two Obp3 variants (see Figure 4 ). The amino acid changes were tentatively identified and their confirmation on the mRNA and protein level is a subject of ongoing projects. Complete results of Mascot searches against Obp sequences library including amino acid corrections for Obp3 are available in Additional file 1.

\section{Discussion}

Wild caught $M$. glareolus voles transcribe (and translate) three novel Obp genes highly similar to those previously described as hamster Aphrodisin. Exon 2, encoding the first sheet of beta barrel, includes a specific signature in amino acid sequence $(\mathrm{GxW})$ that places these novel genes to a family of proteins called lipocalins. As in mouse and hamster these Myodes Obp genes also include specific amino acid feature $\operatorname{CxxxC}$ which is known to form disulphide bond in hamster Aphrodisin. For its ability to form a pheromone-carrying beta barrel this protein is important as it may have overtaken the role of Major Urinary Proteins (Mups) in those species where Mups are not present or are expressed in low quantities. This argument is further supported by studies that show Mups being important in individual recognition and mate choice $[17,51]$. If lipocalins are generally important in these processes they must by substituted by a similar sort of proteins in those species where the expression of Mups is lost.

M. glareolus Obp (i.e. Obp1, Obp2, Obp3) mRNA derived nucleotide sequences (cDNA) were aligned against the corresponding consensus sequences from the Mus, Rattus, and Cricetus sequences from NCBI library. The analyses of replicate trees in which the associated taxa/proteins clustered together revealed that novel Myodes Obps cluster together with Cricetus Aphrodisin, thus, forming a parallel cluster to mouse Obp1a, Obp1b and remaining Mus Obps (bootstrap = 100) previously described as O4-O8 in Stopková et al. [16]. To add, both Cricetus Aphrodisin and Myodes Obp form a group of proteins that, due to a high structural similarity may also serve similar functions where a capacity to bind and transport pheromones by Cricetus Aphrodisin has already been documented [21,52]. Furthermore, the 


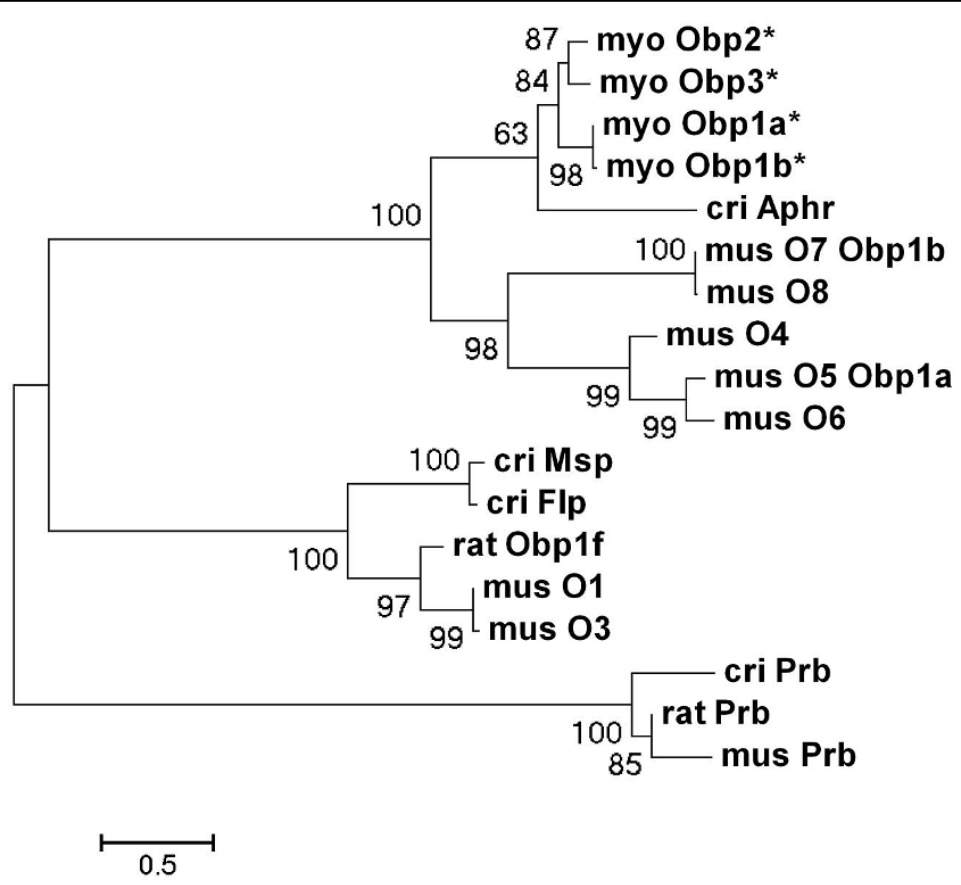

Figure 2 The evolutionary history of Obp using the Neighbour-Joining method. Novel sequences of Myodes glareolus are marked with * and described as myo Obp1-3. Mouse Obp sequences are depicted as mus 01-08 assigned with respective synonyms Obp1a and Obp1b. Known lipocalin sequences from Cricetus cricetus are Aphrodisin (cri Aphr), Male salivary protein (cri Msp), Female lacrimal protein (cri Flp) and Probasin (cri Prb). In Rattus norvegicus the only two lipocalins belonging to this cluster are Obp1f (rat Obp1f) and Probasin (rat Prb). The optimal tree with the sum of branch length $=11.92163796$ is shown. The percentage of replicate trees in which the associated taxa clustered together in the bootstrap test (1000 replicates) are shown next to the branches. The tree is drawn to scale, with branch lengths in the same units as those of the evolutionary distances used to infer the phylogenetic tree. The evolutionary distances were computed using the Maximum Composite Likelihood method and are in the units of the number of base substitutions per site. All positions containing gaps and missing data were eliminated from the dataset (Complete deletion option). There were a total of 478 positions in the final dataset. Phylogenetic analyses and this caption were conducted in MEGA4 software [57].

method of clustering in Figure 2 shows that the divergence of Obp-like lipocalins caused by gene duplication preceded a mouse - rat split that occurred 10.3 millions of years ago as well as muroid and cricetid divergence that most likely occurred 22.5 millions years ago [53]. This is seen in Prb (Probasin) with a branching pattern where a mouse - rat split was preceded by a split of the mouse - rat common ancestor from Cricetid rodents (i. e. Cricetus, Myodes etc.).

In contrast to mouse Major Urinary Proteins with 21 genes and 21 pseudogenes, Obps in Myodes glareolus were detected as only three unique transcripts. However, our 2-DE and consequent MS/MS analyses indicate that the number of potential protein products depicted in Figure 3 may be higher and that further analysis is required to uncover other potential genes and/or allelic variants. On the level of proteins the number of detected variants exceeded the number of detected transcripts in case of Obp3 (Figure 4) and several other Obp proteins were detected in low abundant spots.

To add Myodes glareolus Obp is highly similar to Cricetus and Mesocricetus Aphrodisin, however, their expression pattern is different. Contrary to hamsters, $M$. gareolus Obp was detected in both sexes and in all tested tissues whilst it was missing in vaginal flushes or its expression was low. Its absence might have been caused by the fact that the main site of Obp production in this area are prepucial glands which secret this protein in to the vaginal lumen under specific stimuli which our experimental sample collection method did not satisfy.

\section{Conclusions}

Myodes glareolus voles express three novel Aphrodisinlike genes here named as Obp1, Obp2, and Obp3. Proteomic analysis further revealed that there may be further variants of this genes and that they are secreted into urine and saliva. The comparative analysis provided evidence that these transcripts are expressed in all studied tissues and by individuals of both sex. All this evidence - along with the fact that almost identical Obps in other species have binding affinity to pheromones suggests that these proteins may be used in $M$. glareolus for chemical communication similarly as Major Urinary Proteins in mice. 


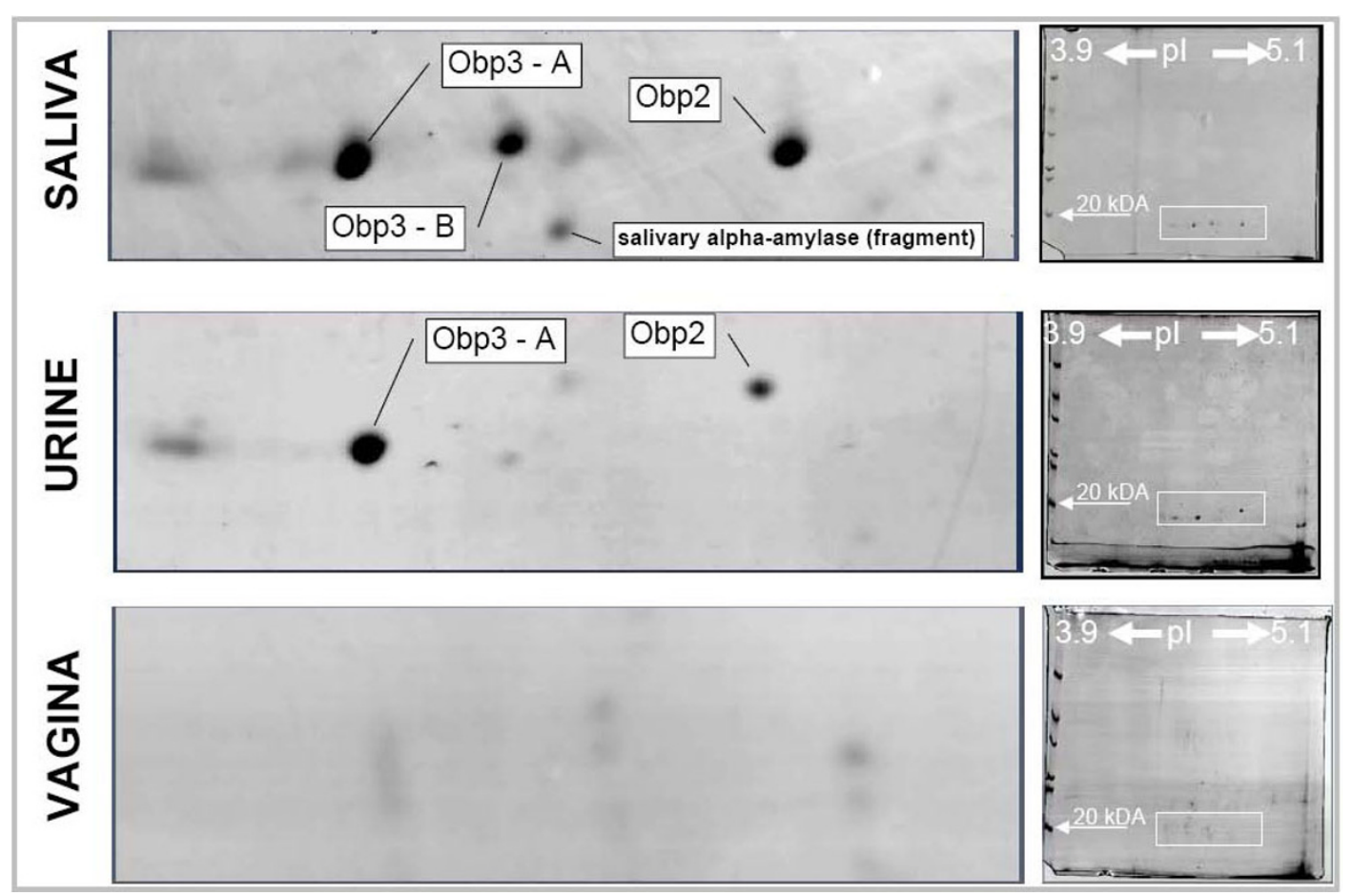

Figure 3 Results 2-DE analysis confirmed the presence of Obp proteins in the urine and saliva. All visible spots have been analyzed with MS/MS techniques where the presence of Obps was detected in most of them. However, only annotated spots (i.e. Obp2, Obp3-A, Obp3-B) were reliably assigned to the particular sequences depicted in Figure 1 and Figure 4.

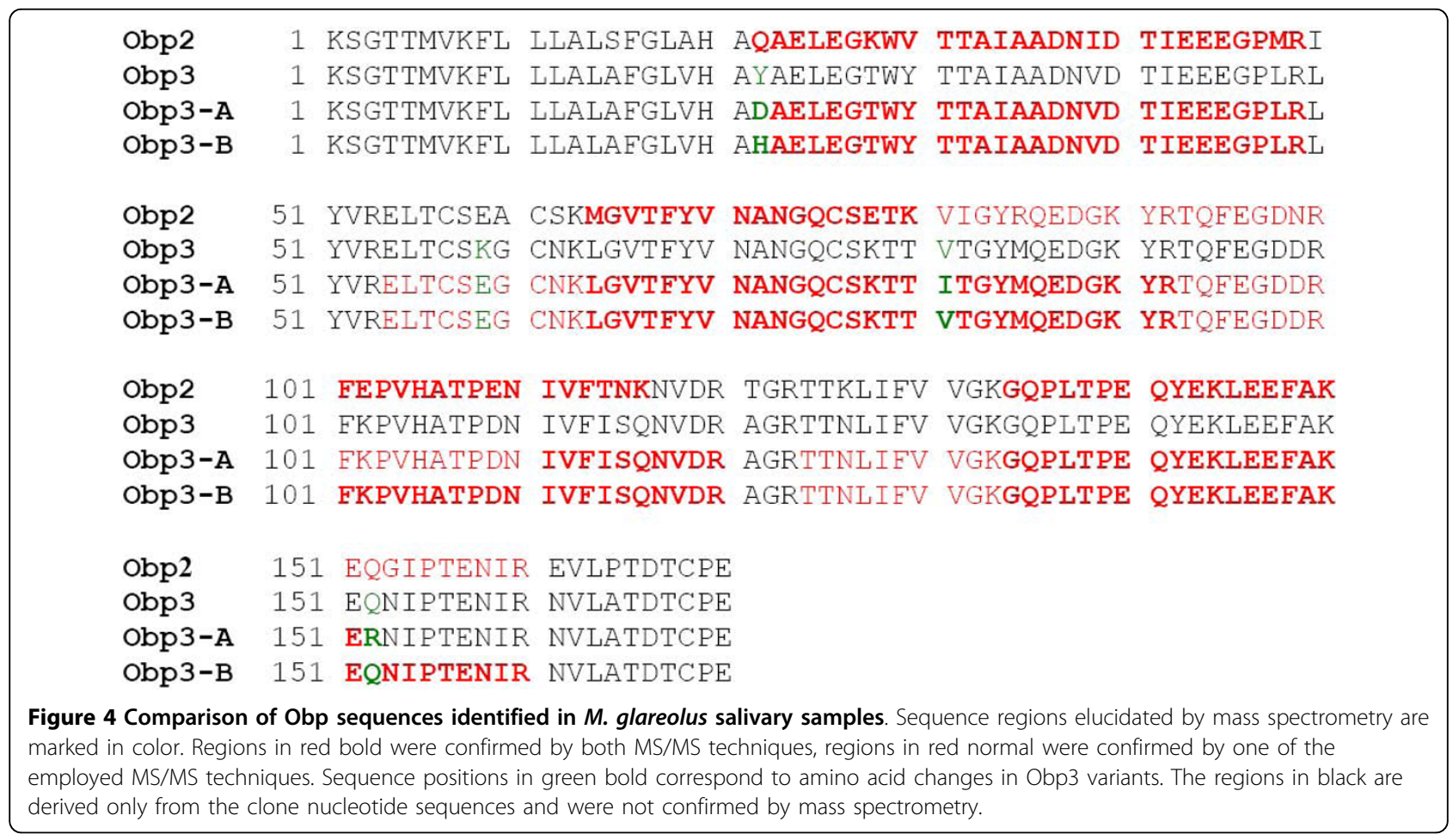




\section{Methods}

\section{Subjects and samples}

The total of twenty individual bank voles (10 males and 10 females, Myodes glareolus) were caught in the Czech Republic in Cernovice near Tabor, near Prague and near Prachov City using the Chmela wild traps. All animals were individually caged with food and water provided ad libitum. All conditions of the Czech law were met to diminish animal suffering under captive rearing. Urine samples were collected in the first half of the 14:10 light period by spontaneous lavage straight to eppendorf tubes, whilst salivary and vaginal samples were collected by gentle flushes with a $10 \mu \mathrm{l}$ Eppendorf tips and with the total volume of $50 \mu \mathrm{l}$ of distilled water.

\section{Analysis of transcripts}

At the day of tissue extraction animals were sacrificed by cervical dislocation and five tissue samples were collected from each animal. Tissue samples were obtained from prepucial/clitorial glands, prostate, liver, parotid glands, submandibular glands and whole uterus tract (without ovaries). Immediately after resection each tissue sample was placed into eppendorff tube with mixture of Trizol (TRIzol Reagent - Invitrogen) and glass pellets and homogenized using mill homogenizator (MM200 Retsch). RNA was isolated using standard Trizol protocol and followed by cDNA synthesis using First strand cDNA synthesis kit (Fermentas).

Various primer sets were tested to amplify the "Aphrodisin" gene, derived from known sequence of hamster Aphrodisin (Mesocricetus auratus, Cricetus cricetus). Finally we set up one pair of primers giving one clear band in the expected area. This primer set covers the whole region from start to stop codon (i.e. Forward: CAAGTCAGGCACCACCATG and Reverse: TTTATTCAGGACAAGTATCTG). Using following conditions for $\mathrm{PCR}$ reaction (denaturation $95^{\circ} \mathrm{C}$ for $30 \mathrm{~s}$, annealing $56^{\circ} \mathrm{C}$ for $30 \mathrm{~s}$ and extension $75^{\circ} \mathrm{C}$ for $50 \mathrm{~s}$, repeated for 35 cycles) we get in all tissues one clear band in the expected range of 515 bp checked in agarose gel. These PCR products from all tissues were purified using QIAquick PCR Purification Kit (Qiagen). We have cloned the PCR product of two males and two females from different tissues separately. Cloning into pCRII TA vector was made as described by the manufacturer (TOPO TA Cloning Kit - Dual promoter, Invitrogen). Clones were sequenced (3130 Genetic Analyzer, Applied Biosystems) using a forward and reverse M13 primers. Sequences were analyzed using Sequence Scanner (Applied Biosystem) software and compared with known sequences from public database NCBI using BLAST. Novel sequences were deposited in GeneBank with the accession numbers provided in the results section.

\section{Protein electrophoresis}

The Bradford method [54] was used to detect appropriate concentration of proteins for further analysis. The total of $5 \mu \mathrm{l}$ (urine), $5 \mu \mathrm{l}$ (saliva), or $11.25 \mu \mathrm{l}$ (vaginal flush) of sample was acetone precipitated. The pellet was diluted in $10 \mu \mathrm{l}$ of SDS sample buffer and heated at $70^{\circ} \mathrm{C}$ for 10 minutes. Separation was performed by means of denaturing polyacrylamide gel electrophoresis (SDS-PAGE) using 10\% NuPAGE ${ }^{\bullet}$ Novex Bis-Tris Midi Gels and NuPAGE ${ }^{\oplus}$ MES Running Buffer (Invitrogen Technologies, Paisley, UK). The gels were stained with the Colloidal Coomassie ${ }^{\circledR}$ G-250 (SimplyBlue ${ }^{\mathrm{Tm}}$ Safe Stain, Invitrogen Life Technologies, Paisley, UK) with images being acquired by GS-800 Calibrated Densitometer.

Two dimensional polyacrylamide elctrophoresis (2DPAGE) was performed with IEF cell (Bio-rad ${ }^{\circ}$ ) and Protean II electrophoresis system. For the first dimension $12 \mu \mathrm{g}$ of proteins was applied to Bio- $\operatorname{Rad} 17 \mathrm{~cm}$ strips (pI: 3.9-5.1). Isoelectric focusing was performed after passive rehydration at room temperature and run at 50 V $9.5 \mathrm{hrs}, 250 \mathrm{~V}$ (rapid) for $15 \mathrm{~min}, 500 \mathrm{~V}$ (rapid), 1000 $\mathrm{V}$ (rapid) for $15 \mathrm{~min}, 10000 \mathrm{~V}$ (rapid) - $35000 \mathrm{~V} / \mathrm{hrs}$, and finished at $500 \mathrm{~V}$ until further step. For the seconddimension separation, the strips were equilibrated for 10 minutes in $45 \mathrm{mM}$ Tris base ( $\mathrm{pH} 7.0)$ containing $6 \mathrm{M}$ urea, $1.6 \%$ SDS, 30\% glycerol, and $130 \mathrm{mM}$ dithiothreitol, and then re-equilibrated for 10 minutes in the same buffer containing $135 \mathrm{mM}$ iodoacetamide in place of dithiothreitol. The strips were then placed on Protean II hand-made $12 \%$ gels, and unstained molecular standards were applied. Second dimension gels were run at constant current - $50 \mathrm{~mA}$ for $1 \mathrm{hr}, 100 \mathrm{~mA}$ for $1 \mathrm{hr}$ and $150 \mathrm{~mA}$ for $1.5 \mathrm{hrs}$ at $10^{\circ} \mathrm{C}$. After electrophoresis, the gels were stained with the Colloidal Coomassie ${ }^{\odot}$ G-250 SSimplyBlue $^{\mathrm{Tm}}$ Safe Stain, Invitrogen Life Technologies, Paisley, UK) with images being acquired by GS-800 Calibrated Densitometer. All spots in the range 15-25 kDa were excised with a Bio-rad Spot Cutter.

\section{Mass Spectrometric Analysis}

Protein spots selected for analysis were excised from 2DE gels. After destaining, the proteins in gel pieces were incubated with trypsin (sequencing grade, Promega) at $37^{\circ} \mathrm{C}$ for $2 \mathrm{~h}$. Digested peptides were extracted from gels using 50\% ACN solution with 5\% formic acid.

MALDI-MS and MS/MS analyses were performed on an Ultraflex III mass spectrometer (Bruker Daltonik, Bremen, Germany). Peptide maps were acquired in reflectron positive mode (25 $\mathrm{kV}$ acceleration voltage) with 800 laser shots. Peaks within 700 - 4000 Da mass range and minimum S/N 10 were picked out for MS/ MS analysis employing LID-LIFT arrangement with 600 laser shots for each peptide. CHCA solution prepared according to Havlis [55] was used as the matrix 
in combination with AnchorChip target to enhance measurement sensitivity. Sample $(1 \mu \mathrm{l})$ was mixed with matrix solution on the target in a 2:1 ratio. Known autoproteolytic products of trypsin were used for internal calibration of digested peptides. In the absence of these products, an external calibration procedure was employed, using a mixture of seven peptide standards (Bruker Daltonik) covering the mass range of 10003100 Da. The Flex Analysis 3.0 and MS Biotools 3.1 (Bruker Daltonik) software were used for data processing.

LC-MS/MS experiments were accomplished on an HPLC system consisting of a gradient pump (Ultimate), autosampler (Famos) and column switching device (Switchos; LC Packings, Amsterdam, The Netherlands) on-line coupled with an HCTultra PTM Discovery System ion trap mass spectrometer (Bruker Daltonik). Tryptic digests were concentrated and desalted using PepMap C18 trapping column $(300 \mu \mathrm{m} \times 5 \mathrm{~mm}$, LC Packings). Sample volume was $15 \mu$ l. After washing with $0.1 \%$ formic acid, the peptides were eluted from the trapping column using an acetonitrile/water gradient (4 $\mu \mathrm{L} / \mathrm{min})$ onto a fused-silica capillary column $(320 \mu \mathrm{m} \times$ $180 \mathrm{~mm}$ ), on which peptides were separated. This column was filled with 4- $\mu \mathrm{m}$ Jupiter Proteo sorbent (Phenomenex, Torrance, CA) according to a previously described procedure [56]. The mobile phase A consisted of acetonitrile $/ 0.1 \%$ formic acid $(5 / 95 \mathrm{v} / \mathrm{v})$ mixture and the mobile phase B consisted of acetonitrile/ $0.1 \%$ formic acid $(80 / 20 \mathrm{v} / \mathrm{v})$ mixture. The gradient elution started at $5 \%$ of mobile phase $\mathrm{B}$, and after 4 minutes, it was increased linearly from $5 \%$ to $50 \%$ during 55 minutes. The analytical column outlet was connected to the electrospray ion source via a $50-\mu \mathrm{m}$-inner diameter fusedsilica capillary. Nitrogen was used as nebulizing as well as drying gas. The pressure of nebulizing gas was 15 psi. The temperature and flow rate of drying gas were set to $300^{\circ} \mathrm{C}$ and $6 \mathrm{~L} / \mathrm{min}$, respectively, and the capillary voltage was $4.0 \mathrm{kV}$. The mass spectrometer was operated in the positive ion mode in a $\mathrm{m} / \mathrm{z}$ range of $300-1500$ for MS and 100-3000 for MS/MS scans. Extraction of the mass spectra from the chromatograms, mass annotation and deconvolution of the mass spectra were performed using DataAnalysis 4.0 software (Bruker Daltonik).

\section{Data Processing}

MASCOT 2.2 (MatrixScience, London, UK) search engine was used for processing the MS and MS/MS data. Database searches were done against the NCBI protein database (Release 20090210) as well as against translated sequence data obtained by TOPO cloning experiment. A mass tolerance of $60 \mathrm{ppm}$ was allowed during processing MALDI MS data for PMF and 0.7 Da during processing LID-LIFT data for MS/MS ion searches. For ESI-MS/MS data, mass tolerances of peptides and MS/MS fragments for MS/MS ion searches were $0.5 \mathrm{Da}$. All searches were done without taxonomic restriction. Both trypsin and semitrypsin as an enzyme were selected for each sample. Oxidation (M), carbamidomethylation $(\mathrm{C})$, deamidation $(\mathrm{N}, \mathrm{Q})$ and pyro-Glu $(\mathrm{Q}, \mathrm{N}$-term) as optional modifications and up to three enzyme miscleavages were set for all searches. Unassigned MS/MS spectra were subjected to manual interpretation to elucidate peptide primary structure and its changes from given sequence data.

Additional file 1: Final Results of Mascot MS/MS Ion Search. The file contains the list of peptides identified by Mascot MS/MS Ion Search for particular Obps.

Click here for file

[http://www.biomedcentral.com/content/supplementary/1471-2164-1145-S1.pdf]

\section{Acknowledgements}

The team members acknowledge the financial support of the Ministry of Education, Youth and Sports (MSM0021620828 and GA AV c. IAA601110908 PS, RS, ŠR, MŠ, MSM0021622415 and LC06034 - OS, ZZ). PS, RS, MŠ also acknowledge the support of the Grant Agency of the Czech Republic (206/ 07/0779).

\section{Author details}

'Department of Zoology, Faculty of Science, Charles University in Prague, Viničná 7, Prague, CZ-128 44, Czech Republic. ${ }^{2}$ Department of Functional Genomics and Proteomics, Institute of Experimental Biology, Faculty of Science, Masaryk University, Brno, Kamenice 5 (A2), Brno, CZ-625 00, Czech Republic.

\section{Authors' contributions}

RS designed primers screened different individuals and tissues, sequenced all transcripts and prepared the draft of this manuscript. ZZ and OS performed all MS analysis including tryptic digestions and consequent analysis of MS/ MS spectra. ŠR performed clonning. MŠ coordinated the sacrificing and with RS performed disections and collected all the mRNA and protein samples. PS coordinated the project, prepared protein gels (2-DE) and helped with the manuscript. All authors have read and approved the final manuscript.

Received: 28 May 2009

Accepted: 19 January 2010 Published: 19 January 2010

\section{References}

1. Novotny M, Harvey $\mathrm{S}$, Jemiolo B: Chemistry of male dominance in the house mouse, Mus domesticus. Experientia 1990, 46:109-113.

2. Novotny MV, Harvey S, Jemiolo B, Alberts J: Synthetic pheromones that promote inter-male aggression in mice. Proc Natl Acad Sci USA 1985, 82:2059-2061.

3. Lin DY, Zhang S-Z, Block E, Katz LC: Encoding social signals in the mouse main olfactory bulb. Nature 2005, 434:470-477.

4. Chamero P, Marton TF, Logan DW, Flanagan K, Cruz JR, Saghatelian A, Cravatt BF, Stowers L: Identification of protein pheromones that promote aggressive behaviour. Nature 2007, 450:899-903.

5. Janotová K, Stopka P: Mechanisms of chemical communication: the role of Major Urinary Proteins. Folia Zool 2009, 58(Supplement 1):41-55.

6. Rusu AS, Krackow S, Jedelsky PL, Stopka P, Konig B: A qualitative investigation of major urinary proteins in relation to the onset of aggressive behavior and dispersive motivation in male wild house mice (Mus musculus domesticus). Journal of Ethology 2008, 26:127-135. 
7. Stopková R, Stopka P, Janotová K, Jedelský PL: Species-specific expression of major urinary proteins in the house mice (Mus musculus musculus and Mus musculus domesticus). J Chem Ecol 2007, 33:861-869.

8. Stopka P, Janotova K, Heyrovsky D: The advertisement role of major urinary proteins in mice. Physiology \& Behavior 2007, 91:667-670.

9. Novotny MV, Ma W, Wiesler D, Zídek L: Positive identification of the puberty-accelerating pheromone of the house mouse: the volatile ligands associating with the major urinary protein. Proc $R$ Soc Lond $B$ 1999, 266:2017-2022

10. Bacchini A, Gaetani E, Cavaggioni A: Pheromone binding proteins of the mouse, Mus musculus. Experientia 1992, 48:419-421.

11. Zidek L, Stone MJ, Lato SM, Pagel MD, Miao Z, Ellington AD, Novotny MV: NMR Mapping of the Recombinant Mouse Major Urinary Protein I Binding site Occupied by the Pheromone 2-sec-Butyl-4,5dihydrothiazole. Biochemistry 1999, 38:9850-9861.

12. Mucignat-Caretta C, Caretta A, Cavaggioni A: Acceleration of puberty onset in female mice by male urinary proteins. Journal of Physiology 1995, 486(2):517-522.

13. Krieger J, Schmitt A, Lobel D, Gudermann T, Schultz G, Breer H, Boekhoff I: Selective activation of $\mathrm{G}$ protein subtypes in the vomeronasal organ upon stimulation with urine-derived compounds. The Journal of Biological Chemistry 1999, 274(8):4655-4662

14. Singer AG, Clancy AN, Macrides F, Agosta WC, Bronson FH: Chemical Properties of a Female Mouse Pheromone that Stimulates Gonadotropin Secretion in Males. Biology of Reproduction 1988, 38:193-199.

15. Logan DW, Marton TF, Stowers L: Species Specificity in Major Urinary Proteins by Parallel Evolution. PLOS ONE 2008, 3, doi: 10.1371/journal. pone.0003280.

16. Stopková R, Hladovcová D, J K, Vyoral D, Stopka P: Multiple roles of secretory lipocalins (MUP, OBP) in mice. Folia Zool 2009, 58(Supplement 1):29-40.

17. Hurst JL, Payne CENc, Marie AD, Humphries RE, Robertson DHL, Cavaggioni A, Beynon RJ: Individual recognition in mice mediated by major urinary proteins. Nature 2001, 414:631-634.

18. Singer A, Macrides F, Clancy AN, Agosta WC: Purification and Analysis of a Proteinaceous Aphrodisiac Pheromone from Hamster Vaginal Discharge. Journal of Biological Chemistry 1986, 261:13323-13326.

19. Macrides F, Clancy AN, Singer AG, Agosta WC: Male hamster investigatory and copulatory responses to vaginal discharge: An attempt to impart sexual significance to an arbitrary chemosensory stimulus. Physiology \& Behavior 1984, 33:627-632.

20. Singer A, Macrides F: Aphrodisin: pheromone or transucer?. Chemical Senses 1990, 15:199-203.

21. Briand L, Blon F, Trotier D, Pernollet J-C: Natural ligands of hamster aphrodisin. Chem Senses 2004, 29:425-430

22. Magert HJ, Hadrys T, Cieslak A, Groger A, Feller S, Forssmann WG: cDNA sequence and expression pattern of the putative pheromone carrier aphrodisin. Proc Natl Acad Sci USA 1995, 92:2091-2095.

23. Kruhoffer M, Bub A, Cieslak A, adermann K, Kunstyr I, Forssmann WG, Magert HJ: Gene expression of aphrodisin in female hamster genital tract segments. Cell Tissue Res 1997, 287:153-160.

24. Magert HJ, Cieslak A, Alkan O, Luscher B, Kauffels W, Forssmann WG: The Golden Hamster Aphrodisin Gene. Journal of Biological Chemistry 1999, 274:444-450.

25. Ganfornina MD, Gutierrez G, Bastiani M, Sanchez D: A Phylogenetic analysis of the Lipocalin Protein Family. MolBioEvol 2000, 17:114-126,

26. Sanchez D, Ganfornina MD, Gutierrez G, Marin A: Exon-Intron Structure and Evolution of the Lipocalin Gene Family. MolBioEvol 2003, 20:775-783.

27. Pes D, Dal Monte M, Ganni M, Pelosi P: Isolation of two odorant-binding proteins from mouse nasal tissue. Comp Biochem Physiol 1992, 103B(4):1011-1017.

28. Flower D: The lipocalin protein family: structure and function. Biochem 1996, 318:1-14.

29. Vincent F, Lobel D, Brown K, Spinelli S, Grote P, Breer H, Cambillau C, Tegoni M: Crystal Structure of Aphrodisin, a Sex Pheromone from Female Hamster. J Mol Biol 2001, 305:459-469.

30. Thavathiru E, Jana NR, De PK: Abundant secretory lipocalins displaying male and lactation-specific expression in adult hamster submandibular gland CDNA cloning and sex hormone-regulated repression. Eur J Biochem 1999, 266:467-476.
31. Ranganathan V, Jana NR, De PK: Hormonal effects on hamster lacrimal gland female-specific major $20 \mathrm{kDa}$ secretory protein and its immunological similarity with submandibular gland major male-specific proteins. Journal of Steroid Biochemistry and Molecular Biology 1999, 70:151-158.

32. Srikantan S, De PK: Sex differences in expression and differential regulation by androgen and estrogen of two odorant-binding tear lipocalins in lacrimal glands. General and Comparative Endocrinology 2008, 158:268-276.

33. Pevsner J, Hou V, Snowman AM, Snyder SH: Odorant-binding Protein. The Journal of Biological Chemistry 1990, 265:6118-6125.

34. Dal Monte M, Andreini I, Revoltella R, Pelosi P: Purification and characterization of two odorant binding proteins from nasal tissue of rabbit and pig. Comp Biochem Physiol 1991, 99B:445-451.

35. Lazar J, Greenwood dR, Rasmussen LEL, Prestwich GD: Molecular and Functional Characterization of an Odorant Binding Protein of the Asian Elephant, Elephas maximus: Implications for the Role of Lipocalins in Mammalian Olfaction. Biochemistry 2002, 41:11786-11794.

36. Briand L, Nespoulous C, Perez V, Remy J, Huet J, Pernollet J: Ligandbinding properties and structural characterization of a novel rat odorant-binding protein variant. Eur J Biochem 2000, 267:3079-3089.

37. Bignetti E, Cavaggioni A, Pelosi P, Persaud KC, Sorbi RT, Tirindelli R: Purification and characterisation of an odorant-binding protein from cow nasal tissue. Eur J Biochem 1985, 149:227-231.

38. Pes D, Pelosi P: Odorant-binding proteins of the mouse. Comp Biochem Physiol 1995, 112B:471-479.

39. Pevsner J, Reed RR, Feinstein P, Snyder SH: Molecular Cloning of OdorantBinding Protein: Member of a Ligand Carrier Family. Science 1988, 241:336-339.

40. Steinbrecht RA: Odorant-Binding Proteins: Expression and Function. Annals of the New York Academy of Sciences 1998, 855:323-332.

41. Tegoni M, Pelosi P, Vincent F, Spinelli S, Campanacci V, Grolli S, Ramoni R, Cambillau C: Mammalian odorant binding proteins. Biochimica et Biophysica Acta 2000, 1482:229-240.

42. Vidic J, Grosclaude J, Momnnerie R, Persuy MA, Badonnel K, Baly C, Caillol M, Briand L, Salesse R, Pajot-Augy E: On a chip demonstration of a functional role for Odorant Binding Protein in the preservation of olfactory receptor activity at high odorant concentration. Lab Chip 2008, 8:678-688

43. Taylor AJ, Cook DJ, Scott DJ: Role of Odorant Binding Proteins: Comparing Hypothetical Mechamisms with Experimental Data. Chem Percept 2008, 1:153-162.

44. Boudjelal M, Sivaprasadarao A, Findlay JBC: Membrane receptor for odourbinding proteins. Biochem J 1996, 317:23-27.

45. Grolli S, Merli E, Conti v, Scaltriti E, Ramoni R: Odorant binding protein has the biochemical properties of a scavenger for 4-hydroxy-2-nonenal in mammalian nasal mucosa. FEBS Journal 2006, 273:5131-5514.

46. Goetz DH, Holmes MA, Borregaard N, Bluhm ME, Raymond KN, Strong RK: The Neutrophil Lipocalin NGAL Is a Bacteriostatic Agent that Interferes with Siderophore-Mediated Iron Acquisition. Molecular Cell 2002, 10:1033-1043.

47. Fischbach MA, Lin H, Zhou L, Yu Y, Aberge RJ, Liu DR, Raymond KN, Wanner Bl, Strong RK, Walsh CT, et al: The pathogen-associated iroA gene cluster mediates bacterial evasion of lipocalin 2. PNAS 2006, 103:16502-16507.

48. Smith KD: Iron metabolism at the host pathogen interface: Lipocalin 2 and the pathogen-associated iro A gene cluster. The International Journal of Biochemistry \& Cell Biology 2007, 39:1776-1780.

49. Strong RK: Siderocalins. Lipocalins Georgetown, Texas: Landes bioscienceAkerstrom B, Borregaard N, Flower DR, Salier JP 2006, 83-98.

50. Salier J: Chromosomal location, exon/intron organization and evolution of lipocalin genes. Biochimica et Biophysica Acta 2000, 1482:25-34.

51. Thom MD, Hurst JL: Individual recognition by scent. Ann Zool Fennici 2004, 41:765-787.

52. Briand L, Huet J-C, Perez V, Lenoir G, Nespoulous C, Boucher Y, Trotier D, Pernollet J-C: Odorant and pheromone binding by aphrodisin, a hamster aphrodisiac protein. FEBS Letters 2000, 476:179-185.

53. Steppan SJ, Adkins RM, Anderson C: Phylogeny and Divergence-Date Estimates of Rapid Radiations in Muroid Rodents Based on Multiple Nuclear Genes. Syst Biol 2004, 53:533-553. 
54. Bradford MM: A Rapid and Sensitive Method for the Quantitation of Microgram Quantities of Protein Utilizing the Principle of Protein-Dye Binding. Analytical biochemistry 1976, 72:248-254.

55. Havlis J, Thomas H, Sebela M, Shevchenko A: Fast-response proteomics by accelerated in-gel digestion of proteins. Anal Chem 2003, 75(6):1300-1306.

56. Planeta J, Karásek J, Vejrosta P: Development of packed capillary columns using carbon dioxide slurries. J Sep Sci 2003, 26(6-7):525-530.

57. Tamura K, Dudley J, Nei M, Kumar S: MEGA4: Molecular Evolutionary Genetics analysis (MEGA) software version 4.0. Molecular Biology and Evolution 2007, 24:1596-1599.

doi:10.1186/1471-2164-11-45

Cite this article as: Stopková et al:: Novel OBP genes similar to hamster Aphrodisin in the bank vole, Myodes glareolus. BMC Genomics 2010 11:45.

Publish with Biomed Central and every scientist can read your work free of charge

"BioMed Central will be the most significant development for disseminating the results of biomedical research in our lifetime. "

Sir Paul Nurse, Cancer Research UK

Your research papers will be:

- available free of charge to the entire biomedical community

- peer reviewed and published immediately upon acceptance

- cited in PubMed and archived on PubMed Central

- yours - you keep the copyright 